\title{
A REFORMA TRIBUTÁRIA ECOLÓGICA ALEMÃ
}

\author{
Roberto Chacon de Albuquerque \\ Doutorando em Direito Civil pela Faculdade de \\ Direito da Universidade de São Paulo
}

Resumo:

O artigo analisa a reforma tributária ecológica alemã, que tem como meta aumentar a eficiência no consumo de energia naquele país, estimulando a venda de produtos que consumam menos combustível ou energia.

Abstract:

The articles analyses the German ecological tributary reform, that has the aim to increase to consumption efficiency on that country, stimulating the sold of products that spends less fuel or energy.

Unitermos: Reforma tributária; imposto; tributação; ecologia; energia; combustível; Alemanha.

\section{Introdução}

A reforma tributária ecológica alemã ${ }^{1}$ constitui um dos projetos-chave para a modernização da economia e da sociedade daquele país. Ela encarece o consumo de energia. Com este encarecimento, tanto empresas quanto residências privadas são estimuladas a investir em tecnologias que reduzam o consumo de energia. As receitas auferidas com a reforma tributária ecológica são utilizadas para reduzir custos salariais, ${ }^{2}$ para facilitar a criação de novos postos de trabalho. Ela teve de ser implementada paulatinamente, para que os contribuintes tivessem tempo para se adaptar ao seu mecanismo de funcionamento. ${ }^{3}$

1. A reforma tributária ccológica alcmã comprecnde tanto a criação do imposto sobre encrgia quanto a majoração do imposto sobrc combustivel.

2. Utilizou-sc, no original alcmão, a cxpressão "Lohnnebenkosten"

3. LOSKE, Reinhard. Vorwort. In: Blick nach vorn. Anforderungen an dic weiteren Stufen der ökologischen Stcuerreform. Bonn: Bündnis 90/Dic Grüncn, II mai 99, p. 2. 
A reforma tributária ecológica alemã constitui também um instrumentochave para combater a mudança climática, ${ }^{4}$ para reduzir o efeito-estufa. ${ }^{5}$ O Ministério do Meio Ambiente alemão reconhece, todavia, que o combate ao efeito-estufa não constitui uma tarefa puramente nacional. A União Européia comprometeu-se a reduzir em $8 \%$ a emissão dos gases que contribuem para agravar o efeito-estufa. ${ }^{6}$ A Alemanha, por sua vez, comprometeu-se a reduzir em $25 \%$ tais emissões de gás, ${ }^{7}$ de 1990 a $2005 .{ }^{8}$ Cerca da metade dessa meta já teria sido alcançada, graças a medidas econômicas que aumentaram a eficiência da indústria e ao próprio colapso das indústrias da antiga República Democrática Alemã. ${ }^{9}$ Alguns setores, no entanto, aumentaram a emissão de gases que contribuem para agravar o efeito-estufa. As residências privadas e o tráfego de automóveis tiveram, respectivamente, um aumento de $8 \%$ e $9 \%$ a mais na emissão de tais gases, de 1990 a $2000 .^{10}$ A reforma tributária ecológica pretende estimular uma maior eficiência no consumo de energia nesses setores.

A reforma tributária ecológica alemã tem como objetivo prioritário a eficiência energética. Na produção de energia, o carvão e a energia nuclear não podem deixar de serem tributados, enquanto o gás natural já é tributado. Seriam duas as alternativas. Ou o carvão e a energia nuclear precisam passar a serem tributados, ou o gás natural, ao menos quando for utilizado em centrais de produção de energia elétrica, precisa deixar de ser tributado." Estas centrais de energia elétrica serão necessárias

4. TRISTTIN, Jürgen. Begrüssung und Einführung. In: Blick nach vorn. Anforderungen an die weiteren Stufen der ökologischen Stcucrreform. Bonn: Bündnis 90/Dic Grünen, 11 mai 99, p. 3: "Der zentrale Punkt in meinen Augen ist, dass die ökologische Steuerreform eines der Schlüsselinstrumente für die Bewältigung der grössten Herausforderung ist, vor der nicht nur die Bundesrepublik, sondern letztendlich alle Bewohner dieses Erdballes stehen: Es geht darum, die Klimaveränderungen mit ihren verheerenden Folgen zu verhindern."

5. Idem, ibidem, p. 3: "Es geht darum, Treibhausgasemissionen zu reduzieren."

6. Id., ib., p. 3: "Die EU hat sich verpflichted, hier um $8 \%$ zu reduzieren."

7. As cmissões são, sobretudo, de CO2 (Cf. ZIESING, Hans-Joachim. Wichtige Baustcine der ÖkoStcucr: Encrgiecffizienz und crncucrbare Encrgien - cinige thesenhafte Überlegungen. In: Blick nach vorn. Anforderungen an die weiteren Stufen der ökologischen Stcuerreform. Bonn: Bündnis 90/Dic Grünen, 11 mai 99, p. 49).

8. Jürgen Tristtin, ob. cit., p. 3: "In Deutschland sind wir da etwas anspruchsvoller: Das Klimareduktionsziel lautet minus 25\% gemessen an 1990 bis zum Jahr 2005."

9. Idem, ibidem, p. 3.

10. Id., ib., p. 3: "Die beiden Bereiche, die hier insbesondere zu nemnen sind, sind die privaten Haushalte und der (übrigens auch aufgrund der Vereinigung) gestiegne Verkehr. In diesen Bereichen, wo wir Entwicklungen von plus $8 \%$ und plus 9\% haben, kann die ökologische Steuerreform eines der Instrumente sein, um tatsächlich zu mehr Verbrauchseffizienz zu kommen."

11. O gás natural ć objeto do imposto sobre combustivel. 
para o abastecimento energético alemão, caso as usinas nucleares forem extintas. As energias renováveis não devem ser tributadas, à exceção das grandes centrais hidroelétricas, ${ }^{12}$ que produzam mais de $5 \mathrm{MW}$. O programa de fomento às energias renováveis - biogás, biomassa e energia solar - deve continuar. Com relação aos setores econômicos que utilizam energia de uma maneira intensiva, pretende-se aumentar o efeito-condutor ${ }^{13}$ da reforma tributária ecológica. Por um lado, as indústrias produtivas pagam um imposto reduzido; por outro lado, implementa-se um mecanismo de compensação. ${ }^{14}$ Os empresários que forem onerados, com a incidência da reforma tributária ecológica, com mais intensidade do que desonerados com a diminuição das contribuições para a seguridade social, podem receber tal importância de volta. ${ }^{15}$

A reforma tributária ecológica alemã tem como meta alterar o paradigma energético, inclusive com a extinção das usinas nucleares. A energia é um bem escasso e finito; o preço para sua utilização na Alemanha é muito reduzido. O preço da energia na Alemanha não estimula a utilização de fontes de energia renovável e o desenvolvimento de tecnologias que reduzam o consumo de energia. ${ }^{16} \mathrm{Com}$ a reforma tributária ecológica, pretende-se reduzir a utilização de fontes de energia não-renováveis, como carvão, óleo ${ }^{17}$ e gás, graças à incidência tributária que encarecerá sua utilização. Por outro lado, criam-se programas de incentivo à utilização de fontes de energia renovável, como a energia solar, eólica e biomassa. ${ }^{18}$ A implementação da reforma tributária ecológica alemã constitui uma tarefa complexa. ${ }^{19}$

12. LOSKE, Reinhard. Dic Ökologische Stcucrreform als Gestaltungsaufgabe - Anforderungen aus Sicht der Bundestagsfraktion. In: Blick nach vorn. Anforderungen an dic weiteren Stufen der ökologischen Stcuerreform. Bonn: Bündnis 90/Dic Grünen, 11 mai 99, p. 8: "Ausnahme davon soll dic grosse Wasserkraft scin."

13. Utilizou-sc, no original alcmão, a cxpressão "Lenkunswirkung"

14. Utilizou-sc, no original alcmão, a cxpressão "Spitzenausgleich".

15. Rcinhard Loske, Dic Ökosteucr-Debatte - Argumente und Hintergründe. In: Blick nach vorn. Anforderungen an die weiteren Stufen der ökologischen Stcuerreform. Bonn: Bündnis 90/Dic Grünen, 08 dezember 2000 , p. 8 .

16. ALEMANHA. Deutscher Bundestag, 14. Wahlperiode. Gesetzentwurf der Fraktionen SPD und BÜNDNIS 90/DIE GRÜNEN; Entwurf cincs Gesctzes zum Einsticg in dic ökologische Stcucrreform, p. I.

17. Utilizou-sc, no original alcmão, a cxpressão “Ör" "Erdöl" significa "pctrólco"

18. (Öko)Stcucrn, dic Sic sich sparen können. Bonn: Bündnis 90/Dic Grüncn, s.d., p. 1.

19. Reinhard Loskc, ob. cit., p. 8: "Es ist schwierig, es ist komplex. Es ist wahrscheinlich mit administrativem Aufwand verbunden." 
Conforme a Declaração para a Proteção do Clima ${ }^{20,}{ }^{21}$ de março de 1995, a indústria alemã comprometeu-se, voluntariamente, a reduzir até 2005 as emissões de $\mathrm{CO}^{2}$ em até $20 \% .^{22}$ De 2008 a 2012, a Alemanha precisa contribuir com uma redução de $21 \%$ na emissão de seis gases que contribuem para agravar o efeito-estufa, para que a meta da União Européia, uma redução conjunta de $8 \%$, seja alcançada. ${ }^{23}$ Todos os portadores de energia que contribuam para o agravamento do efeito-estufa devem ser tributados. A não-tributação da hulha e da lignite, sob o ponto de vista ecológico, não é facilmente sustentável. ${ }^{24} \mathrm{~A}$ reforma tributária ecológica alemã pretende estimular uma utilização mais eficiente dos recursos energéticos, sobretudo no que diz respeito aos combustíveis fósseis. ${ }^{25}$

O setor de transportes é o principal responsável pelos problemas ambientais. Ele é responsável por cerca de $20 \%$ das emissões de CO2. As externalidades negativas do setor de transportes - poluição do ar, sonora e acidentes - oscila entre DM 70 e 250 bilhões por ano na Alemanha. ${ }^{26}$

Os objetivos fundamentais que guiam a reforma tributária ecológica na Alemanha são: esgotar o potencial de aumento da eficiência no consumo de energia de curto prazo; estabelecer práticas contínuas de gestão de energia; e influenciar decisões estratégicas de aumento da eficiência no consumo de energia de longo prazo, que estão ligadas a ciclos de investimento e de inovação. ${ }^{27}$

20. Utilizou-sc, no original alcmão, a expressão "Klimaschutzerklärung".

21. A Declaração para a Proteção do Clima constitui um manifesto da indústria alcmã.

22. KRISTOF, Kora c RAMESOHL, Stephan. Encrgicaudit und Anrechnung von Energiesparmassnahmen. In: Blick nach vorn. Anforderungen an dic weiteren Stufen der ökologischen Stcuerreform. Bonn: Bündnis 90/Dic Grünen, 11 mai 99, p. 46.

23. ZIESING, Hans-Joachim. Wichtige Baustcine der Öko-Steucr: Energiecffizienz und crncucrbare Energien - cinige thesenhafte Überlegungen. In: Blick nach vorn. Anforderungen an dic weiteren Stufen der ökologischen Stcucrreform. Bonn: Bündnis 90/Dic Grüncn, 11 mai 99, p. 49 : "Danach muss bis zum Verpflichtungszeitraum 2008/2012 bei dem Bündel von sechs definierten Treibhausgasen Deutschland eine reduction um $21 \%$ beistenern, um das gemeinsame EU-Ziel von minus $8 \%$ zu realisieren."

24. Idem, ibidem,, p. 52 : "[...] aus ökologischer-Sicht ist die Freistellung der Stein-und Braunkohlen sowie des schweren Heizöls (und-aus anderen Grïnden - der Kernenergie) nur schwer zu begrïnden."

25 -. Diskussionsforum Ökostcucr. Bonn: Bündnis 90/Dic Grüncn, s.d., p. I.

26 LOSKE, Rcinhard c STEFFE, Frank. Dic Ökostcuer-Debatte-Argumente und Hintergründc. In: Blick nach vorn. Anforderungen an die weiteren Stufen der ökologischen Steucrreform. Bonn: Bündnis 90/Dic Grünen, 08 Dezember 2000, p. 5: "Der Verkehrssektor gehört zu den Hauptverwisachern der. bestehenden Umweltprobleme. Er ist für ca. 20\% der CO2-Emissionen verantwortlich; die Schätzungen über die externen Kosten allein des Strassenverkehrs - durch Luftschadstoffe, Lärm und Unfälle schwanken zwischen 70 und über 250 Mrd. DM pro Jahr."

27. Kora Kristof c Stcphan Ramesohl, ob. cit., p. 35. 
Cerca de $52 \%$ dos cidadãos alemães seriam favoráveis à reforma tributária ecológica. ${ }^{28}$

\section{1) A tributação ecológica na Europa}

A Alemanha não é a pioneira na introdução de uma reforma tributária ecológica na Europa. Pelo contrário, a maioria dos países que fazem parte da União Européia já adotaram muitos dos elementos de uma reforma tributária ecológica, sobretudo com uma incidência tributária mais acentuada sobre o consumo de energia. ${ }^{29}$

A Alemanha não constitui, efetivamente, uma pioneira na introdução de uma reforma tributária ecológica na Europa, que já está rumando, faz tempo, para uma "ecologização do sistema tributário"30 Tanto alguns países escandinavos quanto os Países Baixos, bem antes da Alemanha, já adotaram impostos ecológicos. A Alemanha pretende, com efeito, aprender com a experiência já adquirida por esses países como uma reforma tributária ecológica poderia, por exemplo, estimular o consumo de eletrodomésticos e veículos mais econômicos, sob o ponto de vista de consumo de energia." ${ }^{31} \mathrm{O}$ "Fuel Escalator" do Reino Unido, que aumenta a cada ano o imposto sobre combustível ${ }^{32}$ em $6 \%$, também já é conhecido de longa data. As receitas auferidas com a reforma tributária ecológica no Reino Unido têm sido utilizadas em benefício da redução das contribuições dos empregadores para a seguridade social. ${ }^{33}$ Um outro exemplo de reforma tributária ecológica vem da Itália, com o "Imposto-CO2" dentro de uma política de combate ao efeito-estufa, à semelhança da estratégia adotada pela Alemanha. ${ }^{34}$

28. Reinhard Loske c Frank Steffe, ob. cit., p. 4: "Umfiagen in der Süddeutschen Zeitung und im Spiegel haben Mehrheiten (52 bzw. 51\%) zugunsten der Ökosteuer ergeben."

29. SCHLEGELMILCH, Kai. Energiesteuern in Europa - Überblick und Perspektiven. In: Blick nach vorn. Anforderungen an die weiteren Stufen der ökologischen Stcuerreform. Bonn: Bündnis 90/Die Grüncn, II mai 99, p. 10.

30. Tem-sc utilizado, cm alcmão, o neologismo "Ökologisierung des Steuersystems".

31. Jürgen Tristtin, ob. cit., p. 3.

32. Utilizou-sc, no original alcmão, a cxpressào "Mineralölsteuer", cuja tradução literal ć "imposto sobre ólco mincral".

33. Jürgen Tristtin, ob. cit., p. 4: "Grossbitannien ist dadurch bekannt, dass es den sogenannten "Fuel Escalator" - das bedeutet, dass jedes Jahr die Mineralölstener um 6\% steigt - inzwischen durch eine Klimaschutzabgabe für Unternehmen ergäntzt hat, die für dlie Senkung der Sozialversicherungsbeiträge der Arbeitgeber reinvestiert wird."

34. Idem, ibidem, p. 4. 
Tabela 1: Reforma tributária ecológica na Europa

\begin{tabular}{|l|l|}
\hline País & $\begin{array}{l}\text { Ano da Criação/Alteração } \\
\text { do Imposto Ecológico }\end{array}$ \\
\hline Alemanha & 99 \\
\hline Áustria & $95 / 96$ \\
\hline Bélgica & 93 \\
\hline Dinamarca & $92 / 93 / 96 / 00$ \\
\hline Eslovênia & $97 / 98$ \\
\hline Finlândia & $90 / 97$ \\
\hline França & 00 \\
\hline Itália & 99 \\
\hline Noruega & 91 \\
\hline Países Baixos & $92 / 96 / 01$ \\
\hline Reino Unido & $93 / 96 / 01$ \\
\hline Suíça & $97 / 04$ \\
\hline
\end{tabular}

Fonte: SCHLEGELMILCH, Kai. Energiesteuern in Europa - Überblick und Perspektiven. In: Blick nach vorn. Anforderungen an die weiteren Stufen der ökologischen Steuerreform. Bonn: Bündnis 90/Die Grünen, II mai 99, p. 10.

Ainda em 9 de março de 1999, o Reino Unido anunciou que, a partir do mês de abril de 2001, entraria em vigor um imposto sobre o consumo industrial de energia. Já em 1993, o Governo inglês, durante a administração de John Major, procurara tributar com mais intensidade o consumo privado de energia, sobretudo mediante a utilização de óleo para calefação. ${ }^{35}$ Esta iniciativa foi considerada socialmente injusta. O sistema de calefação das residências britânicas não é bom, tampouco o capital disponível por muitas famílias para sua modernização. Tão logo os trabalhistas assumiram o poder, eles reduziram a tributação do consumo privado de energia. Tendo como pano de fundo esta polêmica, o mecanismo revolucionário do "Fuel Escalator" foi adotado sem maiores discussões, ainda em $1993 .{ }^{37}$

35. Utilizou-sc, no original alemão, a cxpressão "Heizöl'.

36. Em março de 1993, o imposto sobre combustível (gasolina c dicscl) passou a sofrer um aumento real, a cada ano, de 3\%. Em novembro de 1993, decidiu-se que csse aumento real, a cada ano, passaria a ser de 5\%. Em 1998, já sob o governo trabalhista, o aumento real, a cada ano, passou a ser de $6 \%$ (Cf. SCHLEGELMILCH, Kai. Energiesteuern in Europa - Überblick und Perspektiven. In: Blick nach vorn. Anfordcrungen an die weiteren Stufen der ökologischen Stcuerreform. Bonn: Bündnis 90/Dic Grünen, 11 mai 99, p. 12).

37. Kai Schlcgclmilch, ob. cit., p. 11. 
A questão central, para o Reino Unido, era descobrir como reduzir o consumo de energia industrial. A emissão de gases que contribuem para agravar o efeito-estufa precisava ser reduzida. A entrada em vigor, a partir de abril de 2001 , de um imposto sobre o consumo industrial de energia foi o caminho escolhido. As contribuições para a seguridade social, da parte do empresariado britânico, deveriam ser reduzidas de $12,2 \%$ para $11,7 \% .{ }^{3 \times}$ Mais de DM 150 milhões devem ser investidos em novas tecnologias ambientais. ${ }^{39}$

A Dinamarca adotou um imposto sobre produção de $\mathrm{CO} 2$ para residências privadas em 15 de maio de 1992 e para indústrias em $1^{\circ}$ de janeiro de 1993 . A reforma tributária ecológica de 1994 compreendeu diferentes tributos ecológicos, como o imposto sobre energia, $\mathrm{CO}^{2}$ e enxofre. A Dinamarca tem protegido a competitividade dos empresários, cuja atividade depende muito do consumo de energia. Os processos de produção que utilizam energia de uma maneira intensiva ${ }^{40}$ são objeto de um imposto reduzido, em comparação aos processos de produção que utilizam energia de uma maneira não intensiva. A Dinamarca tributa com menos intensidade os empresários que se submetem voluntariamente a auditorias de energia ${ }^{41-42}$

Desde a crise do petróleo dos anos 70, a Dinamarca foi um dos únicos países do mundo que manteve artificialmente alto o preço da energia. O objetivo foi tornar rentáveis os investimentos em economia de energia. ${ }^{43}$ A Dinamarca tem utilizado as receitas auferidas com o imposto sobre energia para reduzir custos salariais e para subsidiar investimentos que aumentam a eficiência no consumo de energia. ${ }^{44}$

38. Idem, ibidem, p. 11: "Die Arbeitgeberbeiträge zur Sozialversicherung sollen von 12,2 auf 11,7 Prozentpunkte gesenkt werden."

39. Id., ib., p. 12.

40. Os processos que utilizam encrgia de uma mancira intensiva são definidos $\mathrm{cm}$ função de dois critćrios: as despesas com o imposto devem ser maiores do que $1 \%$ da produção c $3 \%$ do lucro (SCHLEGELMILCH, Kai. Energiesteuern in Europa - Überblick und Perspektiven. In: Blick nach vorn. Anforderungen an dic weiteren Stufen der ökologischen Steuerreform. Bonn: Bündnis 90/Dic Grünen, I] Mai 99, p. 14: "Energieintensive Prozesse sind seitdem über zwei Kriterien definiert: Die Steuerbelastung muss höher sein als ein Prozent des Umsatzes und drei Prozent der Wertschöpfung.").

41. Kora Kristof c Stcphan Ramesohl, ob. cit., p. 36 : "Energie-Audit/Vereinbaung mit Absenkung der Steuersätze als Ausweichmöglichkeit."

42. Kai Schlcgclmilch, ob. cit., p. 17 : "Ausserdem wurden die effektiven Steuersätze für Unternehmen in Abhängigkeit davon modifiziert, ob sie an einem Energieauditing teilnehmen oder nicht."

43. Idem, ibidem, p. 21: "Dänemark hat al einer der wenigen Staaten nach den Ölpreiskrisen der 70 er Jahre das Energiepreisniveau künstlich hochgehalten und nicht verfallen lassen, damit sich die Anstregungen in Energieeinsparung weiterhin rentieren und nicht durch den Ölpreisverfall seit Anfang der 80er Jahre zunichtgemacht werden."

44. Kora Kristof c Stcphan Ramcsohl, ob. cit., p. 36 : "Slenerrückführung durch Lohnnenbenkostensenkung und für Übergangsphase Subventionierung von Energieeffizienzinvestitionen [...]". 
Os Países-Baixos introduziram um imposto sobre gás natural, energia e óleo para calefação em 1992. Como já existia um imposto sobre combustível, ajustado periodicamente em virtude da inflação, nem a gasolina nem o diesel sofreram modificações em seu sistema de tributação. O preço final do gás e da energia em 1998, para pequenos consumidores e residências privadas, aumentou, respectivamente, em $20 \% / 25 \%$ e $15 \% .^{45}$

Para que as camadas com renda mais baixa da sociedade não fossem sobrecarregadas, tanto o consumo de energia de até $800 \mathrm{kWh}$ quanto de gás de até 800 $\mathrm{m} 3$ não foram tributados, seja de residências privadas seja de empresas. ${ }^{46}$ Para que os grandes consumidores não fossem tributados de uma maneira muito intensa, entre 1996 e 1998, as quantias acima de $170 \mathrm{mil} \mathrm{m}^{3}$ de gás e de $50 \mathrm{mil} \mathrm{KWh}$ de energia também não foram tributadas. ${ }^{47}$ A partir de 1998, o limite até o qual se tributou o consumo de energia e de gás passou de 50 mil KWh para 10 milhões de KWh e de $170 \mathrm{mil} \mathrm{m}^{3}$ de gás para 1 milhão de $\mathrm{m}^{3}{ }^{48}$ Os Países-Baixos esperam, até o ano 2000 , ter reduzido, com a tributação do consumo de energia e de gás, as emissões de $\mathrm{CO}^{2} \mathrm{em} 5 \% .{ }^{49}$

Quem explora fontes de energia renováveis, nos Países Baixos, está isento do imposto sobre energia. ${ }^{50}$

A Itália introduziu em 1999 uma reforma tributária ecológica, em cinco etapas, que deverá se prolongar até 2004. A receita auferida deve ser aplicada em benefício da redução dos custos salariais, que deverá atingir $0,8 \% .{ }^{51} \mathrm{O}$ imposto sobre combustível e óleo para calefação será aumentado. Novos impostos, tendo como objeto, por exemplo, o consumo de carvão e de coque, serão criados.

45. Kai Schlegelmilch, ob. cit., p. 19 : "Damit ist der Endpreis von Gas 1998 fïr Kleinverbraucher und Haushalte um 20-25\% und jener von Strom un rund 15\% gestiegen."

46. Idem, ibidem, p. 19: "Um untere Einkomnensgruppen nicht übermässig zu belasten, sind Freimengen von 800 Kilowattstunden Strom sowie 800 Kubikmeter Gas eingeführt worden, die weder Haushalte noch Unternehmen versteuern müssen."

47. Id., ib., p. 19: "Um die (tedenziell eher im Wenbewerb stehenden) Grossverbraucher nicht zut stark zu besteuern, sind anfangs (also konkret zwischen 1996 und 1998) die Mengen oberhalb von 170.000 Kibiknetern Gas und 50.000 Kilowattstunden Strom ebenfalls von der Besteuerung freigestellt."

48. Id., ib., p. 19: "So wird das Limit, bis zu dem Strom und Gas besteuert werden, von $50.000 \mathrm{kWh}$ auf 10 Milliarde $\mathrm{kWh}$ bzw. von $170.000 \mathrm{cbm}$ Gas auf I Million cbm erhöhrt."

49. $1 d .$, ib., p. 19.

50. Id., ib., p. 20: "Schliesslich erhalten die Betreiber regenerativer Energiequellen die Energiestener voll zurückerstattet und sind damit von dieser Steuer befreit."

51. Id., ib., p. 13: "Das Aufkommen soll zurückgegeben werden über eine Senkung der Lohnnebenkosten, bemerkenswerterweise in Höhe der in Deutschland beschlossen Höhe: $0,8 \%$ Prozentpunkte." 
A França adotou em 2000 um imposto sobre energia. Sua receita deve ser parcialmente aplicada no financiamento das contribuições empresariais para a seguridade social. ${ }^{52}$

Os países centro-europeus e europeus orientais dispõem de uma vasta gama de taxas ambientais, cuja efetividade no combate à poluição não tem sido fácil de ser verificada. ${ }^{53}$

Tanto a Comissão quanto o Parlamento da União Européia manifestaramse favoravelmente à adoção de uma diretriz comum em benefício de uma reforma tributária ecológica européia. A tributação da energia, com o objetivo de reduzir a emissão de gases que contribuem para agravar o efeito-estufa, foi recomendada. ${ }^{54}$ Estima-se que os países periféricos ${ }^{55}$ da União Européia se oponham a essa reforma tributária ecológica, sob o argumento de que ela retardaria seu desenvolvimento industrial.

Com a expansão da União Européia ${ }^{56}$ mediante a incorporação de países centro-europeus e europeus orientais, o Governo alemão acredita que o princípio da unanimidade perderá sua operacionalidade. Decisões deveriam passar a sẹr adotadas mediante o princípio da maioria qualificada (3/4). Sendo assim, a construção de alianças com lideranças políticas dos países centro-europeus e europeus orientais torna-se essencial. Tais alianças podem assegurar a adoção de reformas tributárias ecológicas numa União Européia expandida. ${ }^{57}$

\section{2) A reforma tributária ecológica na Alemanha}

A primeira etapa da reforma tributária ecológica entrou em vigor em $1^{\circ}$ de abril de 1999. Algumas imperfeições foram detectadas, como o tratamento desigual conferido ao gás, ao carvão e à gasolina na produção de energia. A utilização de fontes

52. Id., ib., p. 14: "Für das Jahr 2000 ist konkret eine Energiesteuer zur Finanzierung der Arbeitgeberbeiträge zur Sozialversicherung sowie zur Redıktion der Einkommer fïr Bezieher niedrigerArbeitseinkommen - beides im Zusammenhang mit der geplanten obligatorischen Arbeitszeitverkïzunggeplant."

53. Id., ib., p. 13.

54. Jürgen Tristtin, ob. cit., p. 4.

55. Espanha, Grécia, Irlanda, Portugal.

56. A União Europćia passará a ter 25 mcmbros.

57. Kai Schlegelmilch, ob. cit., pp. 24-27. 
de energia renovável foi encarecida. Desconsiderou-se quais seriam os resultados da reforma tributária ecológica na produção de energia elétrica. As indústrias receberam um tratamento diferenciado. ${ }^{58} \mathrm{Na}$ primeira etapa da reforma tributária ecológica, uma desproporção foi detectada. A energia foi muito onerada, enquanto a gasolina, pouco onerada. O Governo alemão considerou essa desproporção insustentável, tanto sob o ponto do meio ambiente quanto da concorrência. ${ }^{5 !}$

Para as segunda e terceira etapas ${ }^{(1)}$ da reforma tributária ecológica, quatro tópicos foram discutidos. Primeiro, um sistema de não-tributação das energias renováveis. Segundo, um sistema de tributação mais eqüitativo para os portadores primários de energia. ${ }^{11}$ Com a reforma tributária ecológica, a utilização do gás foi abertamente discriminada. O gás foi tributado duas vezes, tanto como portador de energia (energia primária) quanto quando ele se transforma em energia. Terceiro, um sistema de tributação mais fortemente orientado para o consumo de energia e produção de $\mathrm{CO}^{2}$. Quarto, um sistema de tributação mais apropriado para as indústrias produtivas. À medida que a atividade produtiva for onerada, a criação de novos postos de trabalho deveria ser desonerada. ${ }^{62}$

A reforma tributária ecológica deve ser concebida como uma reforma a longo prazo. Tanto empresas quanto residências privadas precisam de tempo para adaptar-se à mudança de paradigma energético. ${ }^{63}$ Uma quantidade considerável das emissões de $\mathrm{CO}^{2}$ provém de residências privadas. ${ }^{64}$ À semelhança da Dinamarca e dos Países-Baixos, a Alemanha deveria restituir integralmente o imposto sobre energia

58. LOSKE, Reinhard. Vorwort. In: Blick nach vorn. Anforderungen an die weiteren Stufen der ökologischen Stcuerreform. Bonn: Bündnis 90/Dic Grünen, I1 mai 99, p. 2.

59. LOSKE, Reinhard. Dic Ökologische Stcucrreform als Gestaltungsaufgabe - Anforderungen aus Sicht der Bundestagsfraktion. In: Blick nach vorn. Anforderungen an dic weiteren Stufen der ökologischen Stcucrreform. Bonn: Bündnis 90/Dic Grüncn, 11 mai 99, p. 9: "Es hat in der ersten Stufe der Reform ein gewisses Ungleichgewicht gegeben. Der Strom ist überproportional, Benzin unterproportional belastet worden. Das kann weder umweltpolitisch noch wettbewerbspolitisch so bleiben."

60. As scgunda e terceira ctapas da reforma tributária ccológica entraram cm vigor, respectivamente, $\mathrm{cm} 1^{\circ}$ de janciro de 2000 c $1^{\circ}$ de janciro de 2001.

61. Utilizou-sc, no original alcmão, a expressão "Primärenergieträger"

62. Kora Kristof e Stcphan Ramesohl, ob. cit., p. 40.

63. Hans-Joachim Zicsing, ob. cit., p. 50: "Wirtschaft und private Haushalte benötigen Planungssicherheit, damit Anpassungsmassnahmen und der notwendinge Strukturwandel erlichert werden."

64. (Öko)Stcuern, dic Sic sich sparen können. Bonn: Bündnis 90/Dic Grünen, s.d., p. 1 : “Davon profitiert auch das Klima: Berechnungen haben ergeben, dass ein Grossteil der CO2-Belastungen durch private Haushalte verursacht wird." 
cobrado a quem produz energia renovável. ${ }^{65}$ A reforma tributária ecológica não deveria adotar um modelo excessivamente regulamentador. ${ }^{66}$

Os impostos não apenas financiam as atividades estatais, como podem ter um efeito-condutor direto. $\mathrm{O}$ imposto não deve encarecer indiscriminadamente todas as fontes de energia. Com o encarecimento desproporcional de fontes de energia específicas, o consumo das fontes de energia ilimitadas e não-poluidoras deveria ser estimulado. ${ }^{67}$

A primeira etapa da reforma tributária ecológica alemã criou o imposto sobre energia ${ }^{68}$ e modificou o imposto sobre combustível ${ }^{69-71}$

Com a criação do imposto sobre energia, passou-se a pagar DM 0,02 por kWh. Já com o aumento do imposto sobre combustível, passou-se a pagar DM 0,06 por litro de gasolina ou diesel, DM 0,04 por litro de óleo para calefação e DM 0,32 por $\mathrm{kWh}$ de gás natural. Houve apenas uma etapa da reforma tributária ecológica consagrada ao óleo para calefação, com o aumento, a partir de $1^{\circ}$ de abril de 1999 , da incidência do imposto sobre combustível de DM 0,04 para DM 0,12."

As indústrias produtivas gozam de uma tributação reduzida no consumo de energia de apenas DM 0,05 por kWh, de óleo para calefação, de DM 0,01 por litro e de gás natural de DM 0,08 por $\mathrm{kWh}$. Ainda durante a primeira etapa da reforma tributária ecológica, gerou polêmica o tratamento diferenciado concedido às indústrias produtivas, que têm direito a uma tributação reduzida. A economia de serviços, por exemplo, um grande hotel, não tem direito a esse tratamento diferenciado. ${ }^{72}$

65. Hans-Joachim Zicsing, ob. cit., p. 53.

66. Idem, ibidem, p. 53.

67. Ill., ib., p. 50.

68. Utilizou-sc, no original alemão, a expressão "Stromsteuer"

69. Utilizou-sc, no original alcmão, a expressão "Mineralölsteuer".

70. ALEMANHA. Deutscher Bundestag, 14. Wahlperiode. Gesetzentwurf der Fraktionen SPD und BÜNDNIS 90/DIE GRÜNEN; Entwurf cines Gesctzes zum Einsticg in dic ökologische Stcucrreform, art. I" c art. 2"

71. Reinhard Loske c Frank Steffc, ob. cit., p. 3: "Beim Heizöl gab es im Gegensatz zu den Kraftstoffen nur eine einzige Stufe der Ökosteuer: zum 1.4.1999 wurde die Mineralölsteuer hier um 4 Pfennig auf 12 Pfennig angehoben."

72. HERMANN, Winni. Vorstellung der Ergebnisse der Workshops und anschlicssende Diskussion. In: Blick nach vorn. Anforderungen an die weiteren Stufen der ökologischen Stcucrreform. Bonn: Bündnis 90/Dic Grünen, 11 Mai 99, p. 92: "Die Trennung zwischen produzierendem Gewerbe und Dienstleistungswirtschaft, die im Workshop diskutiert wurde, ist ja auch eine Kontroverse, die uns bereits während der Verhandlung der erten Stufe der ökologischen Steuerreform immer wieder begegnet ist." 
Com a terceira etapa da reforma tributária ecológica, o imposto sobre combustível, incidente sobre gasolina e diesel, aumentou desde $1^{\circ}$ de janeiro de 2001 em DM 0,06 por litro. O imposto sobre energia aumentou DM 0,03 por $\mathrm{kWh}$. O imposto sobre óleo de calefação e gás natural não foi majorado. ${ }^{73}$

A reforma tributária ecológica alemã, em sua primeira etapa, deve ter arrecadado DM 11,3 bilhões. $^{74}$

À semelhança do Reino Unido e da Dinamarca, a Alemanha pretende que a gasolina com alto teor de enxofre custe DM 0,03 mais do que a gasolina com baixo teor de enxofre. Com as segunda e terceira etapas da reforma tributária ecológica, este objetivo teria sido alcançado. O aumento do preço da gasolina com alto teor de enxofre, em função desta tributação seletiva, reduziria seu consumo. Com a diminuição do consumo da gasolina com alto teor de enxofre, as emissões de dióxido de enxofre na atmosfera, provenientes do trânsito de veículos, seriam reduzidas, num curto espaço de tempo, de um quarto a um terço, o que melhoraria a qualidade do ar. ${ }^{75}$ Deseja-se estimular o consumo de gasolina com pouco teor de enxofre, o que melhoraria consideravelmente a situação do meio ambiente.

Para o Governo alemão, a reforma tributária ecológica tem dois aspectos importantes. Primeiro, ela não provoca um êxodo industrial, Segundo, ela estimula a criação de novos postos de trabalho, bem como a manutenção dos já existentes. A reforma tributária ecológica não só fortaleceria a economia de mercado, como alteraria seu curso. A economia de mercado assumiria, aos poucos, uma feição auto-sustentável. ${ }^{76}$

3) Justiça social

O Governo alemão tem acentuado a necessidade de a reforma tributária ecológica ser implementada com justiça social, de uma maneira equilibrada,

73. Ökostcucr: Für cine umweltfrcundliche Energieversorgung. Bonn: Bündnis 90/Dic Grüncn, 9 fcbruar 01, p. 1.

74. ALEMANHA. Deutscher Bundestag, 14. Wahlperiode. Bericht des Haushaltsauschusses (8. Ausschuss) gemäss $\S 96$ der Geschäftsordnung; zu dem Gesetzentwurf der Fraktionen SPD und BÜNDNIS 90/DIE GRÜNEN - Drucksachen 14/40, 14/408, 24 Fcbruar 99. Entwurf cincs Gesctzes zum Einsticg in dic ökologische Stcucrrcform, p. 1: "Der Gesetzentwurf wird durch die Einfiihrung der Stromstener und die Erhöhung der Mineralölstenersätze im Bundeshaushalt im Jahre 1999 zu Mehreimahmen in Höhe von II,3 Mid. DM führen."

75. LOSKE, Rcinhard. Dic Ökologische Stcucrreform als Gestaltungsaufgabe - Anforderungen aus Sicht der Bundestagsfraktion. In: Blick nach vorn. Anforderungen an die weiteren Stufen der ökologischen Stcucrreform. Bonn: Bündnis 90/Dic Grüncn, 11 mai 99, p. 9.

76. Kai Schlcgelmilch, ob. cit., p. 23 . 
especialmente no que diz respeito ao consumo de energia residencial. ${ }^{77}$ A aceitação social da reforma tributária ecológica, para a Alemanha, está associada à conexão entre imposto ecológico e redução dos custos salariais. Caso as receitas auferidas com a receita tributária ecológia forem utilizadas para reduzir déficits orçamentários, a aceitação social da reforma tributária ecológica seria seriamente prejudicada. ${ }^{7 \times} \mathrm{Com}$ a reforma tributária ecológica, novos postos de trabalho devem ser criados. Através da primeira etapa da reforma tributária ecológica, graças à diminuição das contribuições para a seguridade social, mais de 100 mil novos postos de trabalho foram criados. ${ }^{79}$

Com a reforma tributária ecológica, as contribuições para a seguridade social $^{80}$ diminuíram em cerca de $1 \% .^{81}$ Esta diminuição nos custos salariais, que desonera tanto empregadores quanto empregados, estimula a criação de novos postos de trabalho. ${ }^{x 2}$

O efeito desonerador ${ }^{x_{3}}$ da reforma tributária ecológica está vinculado à diminuição das contribuições para a seguridade social. Todavia, nem todos segmentos da população pagam contribuições para a seguridade social. As camadas com renda mais baixa da sociedade precisam ser compensadas de outra maneira. ${ }^{84}$

Graças à reforma tributária ecológica, as residências privadas serão oneradas com o aumento do preço do óleo para calefação, gás natural e energia. ${ }^{{ }^{5.5}}$ Ao

77. LOSKE, Reinhard. Dic Ökologische Stcuerreform als Gestaltungsaufgabe - Anforderungen aus Sicht der Bundestagsfraktion. In: Blick nach vorn. Anforderungen an die weiteren Stufen der ökologischen Stcucrreform. Bonn: Bündnis 90/Dic Grüncn, 11 mai 99, p. 6.

78. Rcinhard Loske, ob. cit., p. 7 : "Wenn die ökologische Steuerreform missbraucht wïrle zum Stopfen von Haushaltslöchern, würde ihre Akzptanz deutlich zurückgehen, und das kann nicht im Interesse aer Ökologie sein."

79. Jürgen Tristtin, ob. cit., p. 3: "Es gibt Berechnungen, dass durch die Senkung der. Sozialversichernngsbeiträge im Rahmen der I. Stufe der ökologischen Stenerreform und durch die Initiativen die sich aus einer solchen Stenerrefom im Positiven ergeben, in den nächsten vier Jahren mit einem Plus von 100.000 zusätzlichen Arbeitsplätzen zurechen ist."

80. Utilizou-sc, no original alemào, a cxpressào "Rentenversicherıng", que poderia scr traduzida, litcralmentc, como "contribuições para a aposentadoria".

81. Rcinhard Loske c Frank Stcffe, ob. cit., p. 4: "Bislang ist der Rentenversicherungsbeitrag dank der Ökosteuer um I Prozentpunkt von 20,3 auf 19,1\% im Jahr 2001 gesunken, ohne Ökosteucr lägen die Beitiäge dagegen bei fast $21 \%$."

82. Diskussionsforum Ökostcucr. Bonn: Bündnis 90/Dic Grüncn, s.d., p. 1.

83. Utilizou-sc, no original alcmão, a cxpressào "Entlastımgswirkung"

84. Rcinhard Loskc, ob. cit., p. 9.

85. LEHR, Ulrike. Unverzichtbar für dic sozialc Ak'́zptanz: Sozialc Gerechtigkcit. In: Blick nach vorn. A forderungen an dic weiteren Stufen der ökologischen Steuerreform. Bonn: Bündnis 90/Dic Grünen, 11 mai 99, p. 54. 
mesmo tempo, elas serão desoneradas com a redução das contribuições dos empregadores para a seguridade social. ${ }^{86}$ As famílias com renda mais baixa poderiam ser desoneradas mediante a concessão de um auxílio-moradia ${ }^{87-88}$ Nem todos, todavia, serão onerados ou desonerados da mesma maneira. ${ }^{89}$

Os aposentados, os desempregados, as camadas com renda mais baixa da sociedade, os estudantes, por exemplo, serão desonerados com baixa intensidade." A reforma tributária ecológica tem um efeito social injusto. As residências com renda mais baixa serão proporcionalmente mais oneradas do que as residências com renda mais alta. ${ }^{91}$

Estima-se que $66 \%$ de todas as familias operárias vivem em imóveis alugados..$^{92}$ As famílias com renda mais baixa vivem, por sua vez, em imóveis mais antigos e baratos, nas quais o custo de aquecimento é maior. ${ }^{93}$ Essas famílias não têm recursos que lhes permitam modernizar o sistema de calefação dos imóveis onde vivem. ${ }^{94}$ Contribuintes que se deslocam para o trabalho de automóvel e não têm nenhuma possibilidade de utilizar outro sistema de transporte, também são especialmente onerados pelo imposto sobre combustível. ${ }^{95}$ Aos locatários, precisa-se oferecer um instrumento de informação que lhes permita, antes de alugar um imóvel, colocar-se a par do gasto médio com energia do mesmo. Não se deve esquecer, todavia,

86. Illem, ibidem, p. 54.

87. Utilizou-sc, no original alcmão, a cxpressão "Wohngeld"

88. O auxilio-moradia beneficia segmentos sociais de baixa renda, como, por excmplo, estudantes, aposentados ou descmpregados (Cf. HEYNE, Kristin. Vorstellung der Ergebnisse der Workshops und anschliessende Diskussion. In: Blick nach vorn. Anforderungen an die weiteren Stufen der ökologischen Stcucrrcform. Bonn: Bündnis 90/Dic Grünen, 11 mai 99, p. 93).

89 Ulrikc Lchr, ob. cit., p. 54: "Die (triviale) Grundannahme ist, dass die Be- und Entlastung nicht für alle Haushaltstypen im gleichen Ausinass gegeben sein wirl."

90 Idem, ibidem, p. 55.

91. Id., ib., p. 55: "Bei diesen Haushalten steht zu vermuten, dass es su 'sozial ungerechten' Effekten kommt; d.h., dass diese Haushalten per Saldo belastet werden, während besser verdienende Haushahte per Saldo sogar entlasted werden."

92. Id., ib., p. 59: "66\% aller Arbeiterhaushalte wolmen zur Miete, dies sind 8,4 Mio. Haushalte."

93. Id., ib., pp. 58-59.

94. Id., ib., p. 56.

95. ALEMANHA. Deutscher Bundestag, 14. Walılpcriode. Bericht des Finanzuschusses (7. Ausschuss); a) zu dem Gesetzentwurf der Fraktionen SPD und BÜNDNIS 90/DIE GRÜNEN - Drucksache $14 / 40$ Entwurf cincs Gesetzes zum Einsticg in dic ökologische Stcuerreform; b) zu dem Antrag der Fraktionen SPD und BÜNDNIS 90/DIE GRÜNEN - Drucksache 14/66 (ncu) - Entlastung durch Einführung cincr ökologischer und sozialen Stcucrrcform, 01 märz 99, p. 19. 
que os custos com a modernização do sistema de calefação gastos pelo locador serão repassados ao locatário. ${ }^{96}$

Para a otimização do efeito-condutor, usuários de energia deveriam entrar em acordo com potenciais investidores em medidas a serem adotadas para minimizar o consumo de energia. ${ }^{97}$

Com a reforma tributária ecológica, os altos custos salariais devem ser reduzidos, ${ }^{98}$ em especial as contribuições para a seguridade social. Ao mesmo tempo, a reforma tributária ecológica deve esgotar o potencial de redução no consumo de energia, bem como estimular a utilização de fontes de energia renovável e o desenvolvimento de tecnologias que reduzam o consumo de energia. ${ }^{99}$

A reforma tributária ecológica não será capaz de eliminar per se a injustiça social. Ela precisa fazer parte de uma reforma tributária mais ampla, com vistas a um combate sistemático às injustiças sociais, que podem ter sua origem até mesmo em como a reforma tributária ecológica tem sido implementada. ${ }^{100}$

A política tributária do Governo alemão pretende desonerar a classe média e diminuir o imposto de renda. O sistema tributário sobrecarregaria, sobretudo, as residências privadas e os pequenos empresários. ${ }^{101}$

4) Auditoria de energia

A reforma tributária ecológica não constitui uma panacéia. Muito pelo contrário, precisam-se adotar medidas como auditorias de energia, mecanismos destinados a estimular a adoção de instrumentos que racionalizem o consumo de energia. ${ }^{102}$

96. Ulrike Lchr, ob. cit., p. 61.

97. Idem, ibidem, p. 66: "Die angestrebte Lenkungswirkung kann so lange nicht erreicht werden, wie die Nutzer von Ewnergie nicht mit den potentiellen Investoren in energiesparende Massnahmen übereinstimmen."

98. Os custos salariais decresceram, graças ao imposto ccológico (Cf. -. Ökologische Steucrreform zcigt nach 2 Jahren crmutigende Lenkunswirkung. Bonn: Bündnis 90/Dic Grüncn, 31 märz 01, p. 1).

99. ALEMANHA. Deutscher Bundestag, 14. Wahlpcriode. Bericht des Haushaltsauschusses (8. Ausschuss) gemäss $\S 96$ der Geschäftsordnung; zu dem Gesctzentwurf der Fraktionen SPD und BÜNDNIS 90/DIE GRÜNEN - Drucksachen 14/40, 14/408, 24 februar 99. Entwurf cincs Gesetzes zum Einsticg in dic ökologische Stcucrreform, p. 1.

100. BERKEL, Matthias. Diskussion der Ergebnisse. In: Blick nach vorn. Anforderungen an dic weiteren Stufen der ökologischen Steuerreform. Bonn: Bündnis 90/Dic Grünen, 11 mai 99, p. 94.

101. Wir treffen - auch wenn die Körbc höher hängen. Bonn: Bündnis 90/Dic Grünen, s.d., p. 1.

102. Kai Schclegclmilch, ob. cit., p. 14: " "[..] eine ökologische Steuerreform allein kein Allheilmittel sei. Statt dessen brauchen wir ergänzende Massnahmen wie Energieaudit, Bewusstseinsbildung und Fördermittel." 
A médio prazo, a Alemanha deve passar a dispor de uma infra-estrutura capaz de viabilizar a realização de auditorias de energia. Como primeiro passo precisará capacitar e credenciar auditores de energia. ${ }^{103}$ As indústrias continuarão a pagar um imposto reduzido, para que permaneçam competitivas internacionalmente. ${ }^{104}$ Paralelamente ao desenvolvimento de um sistema de auditoria de energia, o Estado alemão deveria verificar em que medida uma estrutura de redução da tributação poderia beneficiar as empresas alemãs no mercado internacional. ${ }^{1105}$ Se uma empresa estabelecer práticas de gestão de energia, tanto a segunda quanto a terceira etapas da reforma tributária ecológica não deveriam aumentar a incidência do imposto em relação à primeira etapa da reforma tributária ecológica. ${ }^{10 \%}$

Caso um empresário apresente uma auditoria de energia, atestando a adoção de medidas destinadas ao aumento de eficiência no consumo de energia, ele seria tributado com menor intensidade. O período de amortização sem diminuição da tributação não ultrapassaria oito anos. ${ }^{107}$ Durante o período de amortização, o empresário apresentaria um relatório anual sobre a implementação da estratégia de aumento da eficiência no consumo de energia. Caso as medidas destinadas ao aumento de eficiência no consumo de energia não fossem implementadas dentro do período de amortização, o empresário seria tributado com maior intensidade. ${ }^{108}$

A reforma tributária ecológica não deve sobrecarregar setores econômicos que utilizam energia de uma maneira intensiva, sob risco de torná-los pouco competitivos internacionalmente. As empresas que aumentassem sua eficiência no consumo de energia, deveriam ser recompensadas. Esta recompensa não deveria ser maior do que os gastos do empresário na implementação de sua estratégia de aumento de eficiência

103. Kora Kristof e Stephan Ramesohl, ob. cit., p. 42.

104. Idem, ibidem, p. 40.

105. Id., ib., p. 42: "Parallel zur Weiterentwicklung des Energie-Audit-Systems muss auch untersucht werden, wie die Belastungsfühigkeit der Unternehmen im internationalen Wettbewerb aussieht und wie daran orientierte Steuersatz- und Steuerermässigungsstrukturen geschaffen werden können."

106. Id., ib., p. 40 : "Falls das Unternehmen ein Energiemanagement hat bzw. einfüht (Mindestkriterien dafür sind festzulegen, wobei die Kriterien beim Übergang von der 2. zur 3. Stufe verschärft werden), soll sich keine Steuersteigerung gegenïber der I. Stufe ergeben;"

107. Id., ib., p. 40: "Die Amortisationszeit ohne die Steuerermässigung darf nicht höher als 8 Jahre sein."

108. Id., ib., p. 40: "Falls die Energieeinsparungen in der Amortisationszeit nicht in dem Umfang, in dem sie versprochen wurden, realisiert werden kïnnen, wird entsprechend nachversteuert (incl. Anfallende Zinsen)." 
no consumo de energia, uma vez que essa recompensa não deve se transformar num subsídio. ${ }^{(1)}$

Os empresários que se submetessem voluntariamente a auditorias de energia, para que se verificasse a utilização de mecanismos destinados à economia energética, poderiam ser excluídos da incidência da reforma tributária ecológica, ou ao menos serem submetidos a uma tributação reduzida. Com tal medida, novos postos de trabalho seriam criados, com a redução nos custos do consumo de energia. ${ }^{10}$

Um empresário ou um grupo de empresários pode assinar um acordo (acordo individual ou acordo coletivo, respectivamente) com a Agência de Energia Dinamarquesa (DEA), mediante o qual se submetem voluntariamente a auditorias de energia." Tanto empresários que utilizam energia de uma maneira intensiva quanto empresários que utilizam energia de uma maneira extensiva podem submeter-se, voluntariamente, a auditorias de energia, desde que os gastos com o pagamento dos impostos ecológicos ${ }^{112}$ ultrapassem $3 \%$ de seu lucro e uma quantia mínima estabelecida legalmente. ${ }^{113}$ Um plano de ação, de aumento de eficiência no consumo de energia, tem de ser formulado. Um perito oficial precisa comprovar a idoneidade deste plano de ação. Auditorias de energia, periodicamente, verificam a execução de tal plano. ${ }^{1 / 4}$

5) Subsídios nocivos ao meio ambiente

O término dos subsídios nocivos ao meio ambiente faz parte da reforma tributária ecológica alemã. ${ }^{115-116}$

109. Id., ib., p. 35.

110. LOSKE, Reinhard. Die Ökologische Steuerreform als Gestaltungsaufgabe - Anforderungen aus Sicht der Bundestagsfraktion. In: Blick nach vorn. Anforderungen an die weiteren Stufen der ökologischen Steuerreform. Bonn: Bündnis 90/Die Grünen, II mai 99, p. 8.

111. Kora Kristof e Stephan Ramesohl, ob. cit., p. 37.

112. Imposto sobre energia e imposto sobre combustível majorado.

113. Kora Kristof e Stephan Ramesohl, ob. cit., p. 37 : "Energie-Audit-Berechtigte: Unternelmen mit 'energieintensiven Prozessen' und Unternehmen ohme 'entergieintensive Prozesse', sobald die Steuter 3\% ihrer Wertschöpfung und eine Mindestsumme ïbersteigt."

114. Idem, ibidem, p. 37 : "Um den Aufivand zu senken, erfolgt die generale Untersuchung typischer Einsparpotentiale und die Formulierungs eines Aktionsplans zu ihrer Umsetzung, deren bzw. dessen Quulität von einem unabhängigen behördlich anerkumnten Gutachter zertifiziert wied (formale und technische Überpriifung)."

115. Como a reforma implica a extinção dos subsídios noc vos ao meio ambiente, alguns autores preferem a expressão "reforma financeira ecológica" ("ïkologis : he Finanzreform") a "reforma tributária ecológica" ("ikkologische Steuerreform").

116. MEYER, Bettina. Notwendige Ergänzung: Abbau ökologische schädlicher Subventionen und 
Os subsídios bloqueiam uma alocação racional dos fatores econômicos, à medida que conferem uma vantagem comparativa desproporcional ao setor econômico subsidiado. Subsídios duradouros bloqueiam, além do mais, a modernização da sociedade, à medida em que modificam o ritmo de mudança estrutural da economia. Em virtude do déficit de informação do governo, surge o risco de as "falsas" tecnologias serem subsidiadas. $\mathrm{O}$ governo costuma escolher arbitrariamente quais tecnologias $\mathrm{e}$ setores econômicos serão subsidiados. ${ }^{117}$

Várias são as espécies de subsídios nocivos ao meio ambiente na Alemanha. A título de exemplo, podem-se mencionar os subsídios concedidos à hulha. ${ }^{11 \times}$ O governo também participa do financiamento do transporte dos dejetos nucleares. ${ }^{(1)}$ O preço da energia consumida por fabricantes de alumínio é subsidiado. ${ }^{121}$

Grupos de interesse mobilizam-se contra o término dos subsídios nocivos ao meio ambiente. Costumam ser um grupo pequeno e homogêneo, extremamente sensível ao término desses subsídios. Bem organizados, defendem intensamente seus interesses. $^{121}$

Conclusão

O imposto ecológico transformou-se num instrumento de marketing. Fabricantes de automóveis, empresas de construção, por exemplo, têm utilizado crescentemente o imposto ecológico como meio de alavancar a venda de produtos que consomem menos combustível ou energia. ${ }^{122} \mathrm{O}$ imposto ecológico tem estimulado na Alemanha a fabricação de automóveis que consomem menos combustível, a utilização de meios de transporte públicos, de biomassa e de veículos movidos a gás natural. ${ }^{123}$

Regelungen. In: Blick nach vorn. Anforderungen an die weiteren Stufen der ökologischen Steuerreform. Bonn: Bündnis 90/Die Grünen, 11 mai 99, p. 70: "Der Abbau von ïkologische kontraproduktiven Subventionen ist Teil einer umfassenden ökologischen Finanzreform."

117. Idem, ibidem, p. 7 I.

118. Utilizou-se, no original alemão, a expressão "Steinkohlesubventionen".

119. Bettina Meyer, ob. cit., p. 72.

120. Idem, ibidem, p. 72: "Verbilligungssubventionen z.B. bei Strompreisen für Aluminiumhersteller:"

121. Bettina Meyer, ob. cit., p. 85.

122. Ökologische Steuerreform zeigt nach 2 Jahren ermutigende Lenkunswirkung. Bonn: Bündnis 90/Die Grünen, 31 märz 01, p. I.

123. Ökosteuer: Für eine umweltfreundliche Energieversorgung. Bonn: Bündnis 90/Die Grünen, 9 februar 01, p. 1 . 
A indústria automobilística, em virtude da reforma tributária ecológica, não tem vendido menos automóveis, mas automóveis diferentes, mais eficientes. ${ }^{124}$

Os efeitos positivos do imposto ecológico já se fazem notar. As empresas comunais e regionais têm registrado $1,3 \%$ a mais de passageiros; o interesse em veículos que utilizam menos combustível ou gás natural tem aumentado consideravelmente; e a venda de combustíveis fósseis ${ }^{125}$ diminuiu em cerca de $1,7 \% .^{126}$

A reforma tributária ecológica implica a adoção de um planejamento econômico de longo prazo. A política não pode tornar-se escrava do mercado. ${ }^{127} \mathrm{Em}$ 1960, um trabalhador alemão precisava trabalhar treze minutos para comprar um litro de gasolina. Em 2000, ele precisava trabalhar apenas quatro minutos. ${ }^{12 x}$ A reforma tributária ecológica introduz um instrumento econômico na proteção ao meio ambiente na Alemanha, o que deverá implicar ganhos de eficiência e diminuição de custos no consumo de energia. ${ }^{2 y}$

Toda reforma tributária ecológica deve ser de fácil compreensão, senão será criado um efeito assimétrico. Os grandes empresários terão condições de se adaptarem facilmente à sua lógica, ao contrário dos pequenos. ${ }^{130}$ Indiretamente, a reforma tributária ecológica estaria, assim, contribuindo para que o mercado se tornasse mais oligopolizado.

O imposto sobre combustível ${ }^{131}$ deveria ser substituído por um imposto sobre energia, tendo como componente unificador a emissão de $\mathrm{CO}^{2}{ }^{132-133}$ Toda

124. Reinhard Loske e Frank Steffe, ob. cit., p. 3.

125. Utilizou-se, no original alemão, a expressão "Mineralïlprodukten"

126. Diskussionsforuın Ökosteuer. Bonn: Bündnis 90/Die Grünen, s.d., p. 1.

127. Reinhard Loske e Frank Steffe, ob. cit., p. 4 :

128. Idem, ibidem, p. 5: “1960 musste ein Arbeitmehmer für einen Liter Benzin 13 Mimuten arbeiten, heute dagegen nur 4 Minuten."

129. OECD-Ökonomen bewerten Einstieg in ökologische Steuerreform positiv. Bonn: Bündnis $90 /$ Die Grünen, 08 Dezember 1999, p. I.

130. Winni Hermann, ob. cit., p. 92.

131. Utilizou-se, no original alemão, a expressão "Mineralïlsteuer".

132. O imposto sobre combustível ("Mineraläl") é considerado como sendo ınuito complexo (Cf. HERMANN, Winni. Vorstellung der Ergebnisse der Workshops und anschliessende Diskussion. In: Blick mach vorn. Anforderungen an die weiteren Stufen der ökologischen Steuerreform. Bonn: Bündnis 90/Die Grünen, 11 mai 99, p. 90).

133. Bettina Meyer, ob. cit., p. 75: "Im ergebnis sollten die unsystematischen Einzelsteuersütze der bestehenden Mineralïlsteuer durch eine Energiesteuer (mit CO2-Konponente) ersetzt werden." 
utilização de energia deveria ser objeto desse imposto, tenha ela como objeto o transporte de passageiros ou-não. ${ }^{134}$ Tanto a energia de origem fóssil como atômica deveria ser tributada, ao contrário das fontes de energia renovável. ${ }^{135}$ A utilização de energia em sistemas de transporte deveria ser submetida a uma tributação mais elevada, devido às externalidades negativas, como barulho, acidentes, manutenção da infra-estrutura viária, bem como emissão de gases em áreas residenciais. ${ }^{136}$ Combustíveis pouco nocivos ao meio ambiente, como gás natural, energia elétrica, óleo vegetal, bem como o transporte público, deveriam gozar de uma tributação reduzida. ${ }^{137}$

Não se chegou, ainda, na Alemanha, a um acordo sobre a utilização da receita proveniente da reforma tributária ecológica em benefício de projetos que reduzam o consumo de energia. ${ }^{138}$

São Paulo, maio de 2003.

134. Idem, ibidem, p. 75: "Die Energiesteuer sollte durch ein System von verkehrsspezifischen Zuschlägen ergänzt werden, so dass im Ergebnis alle nicht-verkehrlichen und alle verkehrlichen Verwendungen jeweils nach einem einheitlichen, unweltökonomisch begrïdeten Steuertarif besteuert werden."

135. Id., ib., p. 75.

136. Id., ib., p. 75.

137. Id., ib., p. 76.

138. Winni Hermann, ob. cit., p. 90: "Strittig war noch die Frage, ob ein Teil der Ökosteuereinnahmen auch für Förderprogramme verwendet werden soll, etwa im ÖPNV-Bereich oder beim Bauen, also Energiesparen." 